\title{
DESENVOLVIMENTO INICIAL NO CAMPO DE PESSEGUEIROS 'AURORA-1’ ENXERTADOS EM CLONES DE UMEZEIRO E 'OKINAWA' PROPAGADOS POR ESTACAS HERBÁCEAS ${ }^{1}$
}

\author{
NEWTON ALEX MAYER ${ }^{2}$, FERNANDO MENDES PEREIRA³, VALTER YOSHIO KOBA ${ }^{4}$
}

\begin{abstract}
RESUMO - A presente pesquisa teve por objetivo estudar o desenvolvimento inicial no campo de pessegueiros 'Aurora-1' enxertados nos Clones 05; 10 e 15 de umezeiro (Prunus mume Sieb. et Zucc.) e 'Okinawa' [Prunus persica (L.) Batsch] propagados por estacas herbáceas. O experimento foi conduzido em propriedade rural no município de Taiaçu-SP, em Argissolo Vermelho-Amarelo sob espaçamento de 1,5m x 6,0m, com uso de irrigação por microaspersores subcopa. Foi adotado o delineamento em blocos ao acaso, com quatro tratamentos (porta-enxertos) e cinco repetições, sendo que cada parcela foi constituída de três plantas. Após 23 meses da implantação, foi possível concluir que: a) os portaenxertos Clones 05; 10 e 15 de umezeiro e 'Okinawa' não influenciaram de maneira diferenciada no vigor de pessegueiros 'Aurora-1'; b) o Clone 05 de umezeiro antecipou o pleno florescimento do 'Aurora-1', em relação às plantas enxertadas sobre 'Okinawa'; c) os porta-enxertos estudados não influenciaram no número de frutos por planta e na brotação do 'Aurora-1'; d) não foram observados sintomas de incompatibilidade entre os Clones 05; 10 e 15 de umezeiro e 'Okinawa' propagados por estacas herbáceas com a cv. Aurora-1 de pessegueiro.
\end{abstract}

Palavras-chave: enxertia interespecífica, frutas de caroço, porta-enxerto, Rosaceae.

\section{INITIAL DEVELOPMENT AT FIELD OF 'AURORA-1' PEACH TREES BUDDED ON MUME'S CLONES AND 'OKINAWA' PROPAGATED BY HERBACEOUS CUTTINGS}

\begin{abstract}
The present research had as objective to study the initial development at field of 'Aurora-1' peach trees budded on mume's (Prunus mume Sieb. et Zucc.) Clones 05, 10 and 15 and 'Okinawa' peach [Prunus persica (L.) Batsch] propagated by herbaceous cuttings. The experiment was conducted in a farm in Taiaçu, São Paulo State, Brazil, in Argissolo vermelho-amarelo soil under space 1,5m x 6,0m, with sub-cup irrigation. A randomized blocks design with four treatments (rootstocks) and five replications with three plants was adopted. After 23 months of transplant, was possible to conclude that: a) the rootstocks mume's Clones 05, 10 and 15 and 'Okinawa' peach didn't influence the vigor of 'Aurora-1' peach trees; b) the mume's Clone 05 antecipate the full blossom of 'Aurora-1', in relation to plants budded on 'Okinawa'; c) the evaluated rootstocks didn't influence the fruits number by plant and sprout of 'Aurora-1' peach tree; d) incompatibility symptoms were not observed among the mume's Clones 05,10 and 15 and 'Okinawa' propagated by herbaceous cuttings with 'Aurora-1' peach.
\end{abstract}

Index terms: interespecific bud, stone fruits, rootstock, Rosaceae

\section{INTRODUÇÃO}

Nos programas brasileiros de melhoramento genético do pessegueiro [Prunus persica (L) Batsch], durante muitos anos, foi dada importância somente às cultivares-copa e deixados de lado os porta-enxertos. Desta forma, não existem trabalhos de hibridação no Brasil visando ao melhoramento genético do porta-enxerto, pois é necessário, numa fase inicial, testar aqueles materiais locais ou introduzidos que apresentem potencial (Raseira \& Nakasu, 2002).

Entre as poucas pesquisas desenvolvidas com portaenxertos para pessegueiro no Brasil, destacam-se as realizadas no Instituto Agronômico de Campinas com o umezeiro (Prunus mume Sieb. et Zucc.) (Campo Dall'Orto et al., 1992; Campo Dall'Orto et al., 1994), onde foi observada a viabilidade técnica da enxertia entre as duas espécies, a redução do vigor das plantas, aumentos no teor de sólidos solúveis, da coloração vermelha e da massa dos frutos, em relação aos frutos produzidos pelas mesmas cultivares-copa enxertadas em 'Okinawa' [Prunus persica (L.) Batsch]. Em viveiro, a enxertia de nove cultivares de pessegueiro e duas de nectarineira foi considerada viável em "seedlings" de umezeiro, com redução da altura das mudas e porcentagens de pegamento de enxerto superiores a $70 \%$ (Nakamura et al., 1999).

Em função da grande variabilidade genética que o umezeiro apresenta, decorrente da propagação por sementes, foram iniciados, na Faculdade de Ciências Agrárias e Veterinárias (FCAV/UNESP), Universidade Estadual Paulista (UNESP), Câmpus de Jaboticabal-SP, estudos com a propagação por estacas herbáceas em câmara de nebulização intermitente, visando à manutenção de características genéticas em clones promissores. Desta forma, foram testados os Clones $02 ; 05 ; 10$ e 15 de umezeiro quanto à capacidade de formação de raízes adventícias em estacas herbáceas sob nebulização intermitente (Nachtigal et al., 1999; Mayer, 2001), obtendo-se promissores resultados e comprovando-se a viabilidade do método.

O porta-enxerto influencia em diversas características da cultivar-copa. Em frutas de caroço, exerce efeito sobre: área da seção do tronco, altura da planta, formato, crescimento e volume da copa, comprimento e crescimento de ramos novos, ângulo de abertura dos ramos, absorção de nutrientes, potencial hídrico do xilema, fisiologia da copa, época de floração, produção de frutos, eficiência produtiva, época da senescência das folhas, resistência a doenças e sobrevivência da planta (Hartmann \& Kester, 1978; Young \& Olcott-Reid, 1979; Guerriero et al., 1985; Layne, 1987; Klenyán et al., 1998). Em função do porta-enxerto a ser utilizado, o espaçamento de plantio deve sofrer modificações, bem como outras práticas culturais, tais como o sistema de condução das plantas, o controle de plantas daninhas, o manejo da cobertura verde do pomar e o tipo de sistema de irrigação (Layne, 1987).

Hartmann \& Kester (1978) citam, como sintomas de incompatibilidade entre enxerto e porta-enxerto: falhas em formar a união do enxerto; desenvolvimento excessivo na região de união das partes, acima ou abaixo dela; aparecimento de uma linha necrótica na área de união; amarelecimento das folhas da última estação de crescimento, seguido de desfolha precoce; declínio do crescimento vegetativo; morte dos tecidos periféricos da copa; diferenças acentuadas na taxa de crescimento ou no vigor entre porta-enxerto e enxerto, e morte prematura da planta. Segundo esses autores, a

\footnotetext{
${ }^{1}$ (Trabalho 013-2006). Recebido: 02-02-2006. Aceito para publicação: 30-06-2006. Apoio financeiro: FAPESP (Processo $\mathrm{n}^{\circ}$ 01/00458-0). Parte da Tese de Doutorado do primeiro autor.

${ }^{2}$ Eng. Agr., Dr., Departamento de Produção Vegetal da FCAV/UNESP. Via de Acesso Prof. Paulo Donato Castellane s/n, CEP 14884-900, Jaboticabal-SP. Email: mayersul@yahoo.com.br

${ }^{3}$ Eng. Agr., Dr., Professor Voluntário do Departamento de Produção Vegetal da FCAV/UNESP, Câmpus de Jaboticabal-SP. E-mail: fmendes@fcav.unesp.br ${ }^{4}$ Eng. Agr., gerente da Fazenda São Benedito, Taiaçu-SP. Fone: (16) 3275-1245.
} 
presença isolada de um ou mais destes sintomas não-necessariamente significa que a combinação seja incompatível.

O presente trabalho teve por objetivo estudar o desenvolvimento inicial de pessegueiros 'Aurora-1' em condição de campo, enxertados nos Clones 05; 10 e 15 de umezeiro e 'Okinawa' propagados por estacas herbáceas.

\section{MATERIAL E MÉTODOS}

Foram utilizados, como porta-enxertos, os Clones 05; 10 e 15 de umezeiro e a cv. Okinawa de pessegueiro, cujas plantas-matrizes foram mantidas em área pertencente ao Departamento de Produção Vegetal da FCAV/UNESP, Câmpus de Jaboticabal-SP. A propagação dos porta-enxertos foi realizada em câmara de nebulização intermitente, localizada no "Sítio São João" (Taquaritinga-SP), utilizando-se de estacas herbáceas de $12 \mathrm{~cm}$, colhidas em setembro, com adição de $2.000 \mathrm{mg} . \mathrm{L}^{-1}$ de AIB (Mayer, 2001), e, após o período de enraizamento (70 dias), as estacas enraizadas foram transplantadas para sacos plásticos $(28 \times 18 \mathrm{~cm})$ contendo substrato comercial (Rendmax Citrus $\left.{ }^{\circledR}\right)$. Aos 130 dias após o transplantio (março de 2002), as plantas foram enxertadas com a cv. Aurora-1 de pessegueiro pelo método de borbulhia por escudo (Hartmann \& Kester, 1978) e mantidas em condição de viveiro telado até o início da época das chuvas (novembro de 2002), momento do transplantio para o campo. Nesta ocasião, foi realizada uma seleção visual das mudas, observando-se o diâmetro e a altura, separando-se as mais homogêneas dentro de cada lote para serem levadas ao campo, conforme sugerido por Campo Dall'Orto et al. (1992).

O experimento foi conduzido a campo (de novembro/2002 a outubro/2004), em Argissolo Vermelho-Amarelo (Oliveira et al., 1999) pertencente à "Fazenda São Benedito", localizada no Município de Taiaçu-SP. O preparo do solo foi feito com algumas passagens de um sulcador (aproximadamente $40 \mathrm{~cm}$ de profundidade), numa faixa de 3 metros de largura, no local de implantação da linha do experimento. Em seguida, foi realizada a fertilização de uma faixa de $1 \mathrm{~m}$ de largura do solo, com os seguintes produtos: $1 \mathrm{~kg}$ de calcário dolomítico $/ \mathrm{m}^{2}$, $1 \mathrm{~kg}$ torta de mamona $/ \mathrm{m}^{2}$ e $0,5 \mathrm{~kg}$ de Yoorin ${ }^{\circledR} / \mathrm{m}^{2}$. A incorporação dos produtos foi feita com várias passagens de um cultivador, deixandose, em seguida, o solo em repouso por 15 dias. Para o preparo das covas, foi feito um sulco ( $30 \mathrm{~cm}$ de profundidade) na linha de implantação do experimento, onde pequenas covas foram feitas, com o espaçamento de $1,5 \mathrm{~m} \times 6,0 \mathrm{~m}$. O plantio das mudas no campo foi realizado em 07 de novembro de 2002, preservando-se o torrão que envolve as raízes e não despontando-se da haste principal, para conduzir as plantas em líder central. As mudas foram irrigadas, sempre que necessário, por microaspersão subcopa (Pereira et al., 2002). Durante todo o período de condução do experimento, foram realizadas sete adubações de cobertura, e os tratamentos fitossanitários constaram de nove aplicações (Pereira et al., 2002).

No dia 30 de junho de 2003, foi realizada a primeira poda de formação, cujo objetivo foi definir a estrutura produtiva da planta, retirando-se os ramos oriundos dos porta-enxertos, os ramos menos vigorosos e os malposicionados (Pereira et al., 2002), fazendo com que os ramos laterais ocupassem, da melhor maneira possível, o espaço disponível. A haste principal foi despontada entre 90 e $110 \mathrm{~cm}$ do ponto de enxertia, e todos os ramos remanescentes também foram despontados à metade. Uma semana após, foi feita uma desfolha manual, tomando-se o cuidado para não danificar as gemas e aplicada a cianamida hidrogenada a $0,29 \%$ (Dormex ${ }^{\circledR}$ a $0,6 \%$ ) com pulverizador costal (Nienow, 1997), uniformemente ao redor das plantas até o ponto de gotejamento, utilizando, em média, $143 \mathrm{~mL}$ da solução por planta. A poda de renovação foi realizada em $1^{\circ}$ de dezembro de 2003 (Pereira et al., 2002), com o objetivo de proporcionar novos crescimentos vegetativos, capazes de diferenciar as gemas floríferas a tempo de permitir o florescimento a partir de junho, período em que as temperaturas são mais baixas e favorecem o pegamento dos frutos (Nienow, 1997; Pereira et al., 2002). A segunda poda de produção foi realizada em 12 de julho de 2004, onde foi deixado o maior número de ramos produtivos possível e, em seguida, aplicada a cianamida hidrogenada a $0,29 \%$.

O experimento foi conduzido em blocos casualizados, com 4 tratamentos, constituídos dos porta-enxertos Clones 05; 10 e 15 de umezeiro e cv. Okinawa de pessegueiro, com 5 repetições, sendo que cada parcela foi constituída de 3 plantas, totalizando 60 plantas.

As variáveis analisadas foram o comprimento da haste principal (mensurado com fita métrica a partir do ponto de enxertia) até maio de 2003 (6 meses após o plantio) e o diâmetro do tronco (mensurado com paquímetro digital a $5 \mathrm{~cm}$ acima do ponto de enxertia) avaliado a cada 3 meses, até agosto de 2004 (21 meses após o plantio). Em agosto de 2004, aos 24; 30; 36 e 43 dias após a aplicação da cianamida hidrogenada, foi avaliada a floração, segundo uma escala visual de notas, que variou de 0 (ausência) a 10 (floração completa). No dia 11 de outubro de 2004 (88 dias após a aplicação da cianamida hidrogenada), foi realizado o raleio dos frutos, deixando-se 2 ou 3 frutos por ramo, de acordo com o vigor (Pereira et al., 2002), e realizada a contagem dos frutos raleados por planta. Nove dias depois, foi realizada a contagem do número de frutos restantes por planta e do número de frutos total por planta (raleados + restantes). Foi realizada também uma avaliação visual da brotação da estação de crescimento, baseada numa escala de notas, que variou de 1 (brotação fraca, ramos novos curtos e/ou inadequadamente distribuídos na planta) a 5 (brotação excelente). Os dados foram submetidos à análise de variância, pelo teste $\mathrm{F}$, e as médias, comparadas pelo teste de Tukey, a $5 \%$ de probabilidade.

\section{RESULTADOS E DISCUSSÃO}

Os valores referentes ao comprimento da haste principal são apresentados na Tabela 1. Observa-se que, no momento do plantio, as mudas enxertadas em 'Okinawa' eram mais altas do que as enxertadas nos clones de umezeiro. Diferenças estatísticas também se verificaram entre os clones de umezeiro, sendo que os Clones 10 e 15 apresentaram

TABELA 1 - Comprimento da haste principal $(\mathrm{em} \mathrm{cm})$ de pessegueiros cv. Aurora-1 enxertados em diferente porta-enxertos, sob condições de campo. Taiaçu-SP, maio de 2003.

\begin{tabular}{cccc}
\hline Porta-enxerto & \multicolumn{3}{c}{ Comprimento da haste principal (cm) } \\
\cline { 2 - 4 } & $\begin{array}{c}\text { no plantio } \\
\text { (novembro / 2002) }\end{array}$ & $\begin{array}{c}\text { 3 meses } \\
\text { (fevereiro / 2003) }\end{array}$ & $\begin{array}{c}\text { 6 meses } \\
\text { (maio / 2003) }\end{array}$ \\
\hline Clone 05 & $35,80 \mathrm{~d}$ & $104,53 \mathrm{a}$ & $170,00 \mathrm{a}$ \\
Clone 10 & $48,73 \mathrm{bc}$ & $106,20 \mathrm{a}$ & $159,87 \mathrm{a}$ \\
Clone 15 & $43,87 \mathrm{c}$ & $111,87 \mathrm{a}$ & $176,33 \mathrm{a}$ \\
Okinawa & $63,13 \mathrm{a}$ & $120,98 \mathrm{a}$ & $194,62 \mathrm{a}$ \\
\hline $\mathrm{F}_{\text {tratamentos }}$ & $57,22^{* *}$ & $1,96^{\mathrm{NS}}$ & $2,86^{\mathrm{NS}}$ \\
\hline $\mathrm{F}_{\text {Blocos }}$ & $3,73^{*}$ & $2,79^{\mathrm{NS}}$ & $0,77^{\mathrm{NS}}$ \\
\hline C.V. (\%) & 6,51 & 9,77 & 10,13 \\
\hline
\end{tabular}

Médias seguidas por letras distintas, na mesma coluna, diferem entre si, pelo teste de Tukey. ** significativo ao nível de $1 \%$ de probabilidade; $*$ significativo ao nível de $5 \%$ de probabilidade; ${ }^{\text {NS }}$ não-significativo. 
TABELA 2 - Diâmetro do tronco a $5 \mathrm{~cm}$ acima do ponto de enxertia (em $\mathrm{mm}$ ) de pessegueiros cv. Aurora-1 enxertados em diferentes porta-enxertos, sob condição de campo. Taiaçu-SP, agosto de 2004.

\begin{tabular}{ccccccccc}
\hline \multirow{2}{*}{$\begin{array}{c}\text { Porta- } \\
\text { enxerto }\end{array}$} & $\begin{array}{c}\text { plantio } \\
\text { nov/02 }\end{array}$ & $\begin{array}{c}\mathbf{3} \text { meses } \\
\text { fev/03 }\end{array}$ & $\begin{array}{c}\mathbf{6} \text { meses } \\
\text { maio/03 }\end{array}$ & $\begin{array}{c}\mathbf{9} \text { meses } \\
\text { ago/03 }\end{array}$ & $\begin{array}{c}\mathbf{1 2} \text { meses } \\
\text { nov/03 }\end{array}$ & $\begin{array}{c}\mathbf{1 5} \text { meses } \\
\text { fev/04 }\end{array}$ & $\begin{array}{c}\mathbf{1 8} \text { meses } \\
\text { maio/04 }\end{array}$ & $\begin{array}{c}\mathbf{2 1} \text { meses } \\
\text { ago/04 }\end{array}$ \\
\hline Clone 05 & $4,13 \mathrm{~b}$ & $12,96 \mathrm{~b}$ & $22,98 \mathrm{a}$ & $26,27 \mathrm{a}$ & $35,62 \mathrm{a}$ & $40,45 \mathrm{a}$ & $44,64 \mathrm{a}$ & $46,68 \mathrm{a}$ \\
Clone 10 & $4,98 \mathrm{a}$ & $13,85 \mathrm{ab}$ & $22,94 \mathrm{a}$ & $26,00 \mathrm{a}$ & $36,33 \mathrm{a}$ & $42,11 \mathrm{a}$ & $47,03 \mathrm{a}$ & $48,97 \mathrm{a}$ \\
Clone 15 & $4,90 \mathrm{a}$ & $14,57 \mathrm{ab}$ & $24,70 \mathrm{a}$ & $28,48 \mathrm{a}$ & $39,23 \mathrm{a}$ & $43,99 \mathrm{a}$ & $48,93 \mathrm{a}$ & $49,61 \mathrm{a}$ \\
Okinawa & $5,57 \mathrm{a}$ & $15,85 \mathrm{a}$ & $26,17 \mathrm{a}$ & $29,82 \mathrm{a}$ & $38,63 \mathrm{a}$ & $43,39 \mathrm{a}$ & $48,87 \mathrm{a}$ & $49,96 \mathrm{a}$ \\
\hline $\mathrm{F}_{\text {tratamentos }}$ & $13,66^{* *}$ & $4,04^{*}$ & $3,03^{\mathrm{NS}}$ & $3,50^{\mathrm{NS}}$ & $3,18^{\mathrm{NS}}$ & $2,15^{\mathrm{NS}}$ & $1,89^{\mathrm{NS}}$ & $1,71^{\mathrm{NS}}$ \\
\hline $\mathrm{F}_{\text {Blocos }}$ & $1,18^{\mathrm{NS}}$ & $2,14^{\mathrm{NS}}$ & $2,13^{\mathrm{NS}}$ & $2,15^{\mathrm{NS}}$ & $0,91^{\mathrm{NS}}$ & $1,83^{\mathrm{NS}}$ & $1,55^{\mathrm{NS}}$ & $5,24^{*}$ \\
\hline C.V. $(\%)$ & 6,87 & 8,79 & 7,62 & 7,37 & 5,73 & 5,54 & 6,77 \\
\hline
\end{tabular}

Médias seguidas por letras distintas, na mesma coluna, diferem entre si, pelo teste de Tukey. ** significativo ao nível de $1 \%$ de probabilidade; * significativo ao nível de $5 \%$ de probabilidade; ${ }^{\mathrm{NS}}$ não-significativo.

hastes maiores que o Clone 05. Entretanto, com o passar de apenas três meses no campo, as diferenças em comprimento da haste não mais se observaram, situação verificada também aos 6 meses após o transplantio. Com as três avaliações realizadas, foi possível observar o rápido desenvolvimento das plantas em todos os porta-enxertos estudados. Salienta-se que o comprimento da haste aumentou 1,92 vez no 'Okinawa'; 2,18 vezes no Clone 10; 2,55 vezes no Clone 15, e 2,92 vezes no Clone 05 , nos primeiros três meses após o plantio, o que comprova essas observações. Entre os clones de umezeiro, o Clone 10 foi o que apresentou as menores taxas de crescimento entre as avaliações que, no entanto, não determinou diferença estatística em relação aos demais.

Sob condições de campo, após três anos de avaliações, Campo Dall'Orto et al. (1992) relataram que a cv. Aurora-1 foi uma das cultivares que apresentou melhor comportamento em termos de uniformidade de plantas, compatibilidade inicial da enxertia, equilíbrio entre frutificação/vegetação e número de frutos produzidos, quando enxertada na seleção de umezeiro 'Iacume' (IAC-3). Nestas condições, o umezeiro reduziu o porte das plantas de $2 / 3$ a $1 / 2$ em relação às enxertadas em 'Okinawa'. Estes autores também salientam a necessidade de clonagem do umezeiro, objetivando evitar a grande desuniformidade de vigor entre as plantas quando o porta-enxerto é propagado por sementes.

Os valores relativos ao diâmetro do tronco, a $5 \mathrm{~cm}$ acima do ponto de enxertia, são apresentados na Tabela 2. Observa-se a diferença estatística entre os porta-enxertos no momento do plantio, sendo que o 'Okinawa', Clones 10 e 15 apresentaram médias maiores do que o Clone 05. Assim como observado na variável comprimento da haste, o Clone 05 também apresentou menor diâmetro do tronco em relação aos demais, na avaliação realizada no plantio. Aos três meses, o 'Okinawa' apresentou plantas com diâmetro de tronco maior, em relação àquelas enxertadas no Clone 05. Os Clones 10 e 15 comportaram-se como intermediários, não diferindo estatisticamente dos demais. No entanto, em todas as avaliações realizadas a partir dos seis meses, não foram encontradas diferenças estatísticas entre os porta-enxertos.
Com os resultados obtidos durante os primeiros 21 meses após o plantio das mudas no campo (Tabela 2), pôde-se observar que os clones de umezeiro não reduziram o diâmetro do tronco, em relação ao 'Okinawa', o que contraria as informações da literatura (Campo Dall'Orto et al., 1992; Campo Dall'Orto et al., 1994; Nakamura al., 1999). A semelhança estatística observada no presente estudo entre os quatro porta-enxertos, também não concorda com o observado em estudo realizado com os mesmos porta-enxertos não enxertados (Mayer \& Pereira, 2006), onde se verificou menor vigor do Clone 10. Com estas constatações, pode-se inferir que, provavelmente, esteja ocorrendo o efeito do vigor da cultivar-copa no presente estudo, visto que a medida do diâmetro foi tomada a $5 \mathrm{~cm}$ acima do ponto de enxertia, ou seja, na cultivar-copa. De acordo com Hartmann \& Kester (1978), existem relações entre enxerto e porta-enxerto, e a influência se observa nos dois sentidos, ou seja, o porta-enxerto exerce influência sobre a copa, e vice-versa. Outra provável causa para a igualdade estatística entre os porta-enxertos são as diferenças de solo do presente estudo com o descrito por Mayer \& Pereira (2006). Embora não tenham sido realizadas avaliações físicas dos solos em ambos os experimentos, foi possível observar que o presente estudo foi conduzido em solo mais arenoso. De acordo com Hartmann \& Kester (1978), os porta-enxertos respondem de maneira diferente a certas condições de solo, especialmente umidade, produzindo ou não alterações sobre o comportamento da copa.

De acordo com as notas atribuídas à floração (Tabela 3), pode-se observar que, nas primeiras três avaliações (24; 30 e 36 dias após a aplicação da cianamida hidrogenada), não foi detectada diferença estatística entre os porta-enxertos. Aos 36 dias, o Clone 05 foi o único tratamento em que foi estimado mais de $50 \%$ das flores abertas (nota $=5,73$ ), embora não tenha sido detectada diferença estatística em relação aos demais porta-enxertos. No entanto, aos 43 dias, observa-se que a cv. Aurora-1, enxertada no Clone 05, apresentou maior nota para a floração (correspondente a 83,3\% de flores abertas), em relação ao enxertado no 'Okinawa', significando que o Clone 05 de umezeiro antecipou a floração da cv. Aurora-1, em relação à 'Okinawa'. Estes resultados são interessantes do ponto de vista econômico,

TABELA 3 - Avaliação do florescimento (escala de 0 a 10) de pessegueiros 'Aurora-1', com 21 meses de idade, enxertados nos Clones 05; 10 e 15 de umezeiro e 'Okinawa', em quatro avaliações, após a aplicação da cianamida hidrogenada. Taiaçu-SP, agosto de 2004.

\begin{tabular}{|c|c|c|c|c|}
\hline \multirow{3}{*}{ Porta-enxerto } & \multicolumn{4}{|c|}{ Floração (escala de 0 a 10) } \\
\hline & \multicolumn{4}{|c|}{ Dias após a aplicação de cianamida hidrogenada } \\
\hline & 24 & 30 & 36 & 43 \\
\hline Clone 05 & $1,27 \mathrm{a}$ & $3,60 \mathrm{a}$ & 5,73 a & 8,33 a \\
\hline Clone 10 & $1,13 \mathrm{a}$ & 3,07 a & $4,67 \mathrm{a}$ & $8,13 \mathrm{ab}$ \\
\hline Clone 15 & $1,87 \mathrm{a}$ & 3,67 a & $4,80 \mathrm{a}$ & $8,00 \mathrm{ab}$ \\
\hline Okinawa & $1,98 \mathrm{a}$ & 3,08 a & $3,90 \mathrm{a}$ & $6,82 \mathrm{~b}$ \\
\hline $\mathrm{F}_{\text {Tatam (ajust.) }}$ & $2,65 \mathrm{NS}$ & $0,40^{\mathrm{NS}}$ & $2,39^{\mathrm{NS}}$ & $3,81^{*}$ \\
\hline $\mathrm{F}_{\text {Blocos }}$ & $4,27 *$ & $2,14^{\mathrm{NS}}$ & $1,75^{\mathrm{NS}}$ & $2,13^{\mathrm{NS}}$ \\
\hline C.V. $(\%)$ & 35,56 & 32,75 & 21,38 & 8,95 \\
\hline
\end{tabular}

Médias seguidas por letras distintas, na mesma coluna, diferem entre si, pelo teste de Tukey. * significativo ao nível de $5 \%$ de probabilidade; ${ }^{\text {NS }}$ não-significativo. 
TABELA 4 - Número de frutos raleados por planta, número de frutos restantes por planta, número de frutos totais por planta e nota para brotação da estação de crescimento da cultivar Aurora-1, enxertada em diferentes porta-enxertos sob espaçamento de $6,0 \times 1,5 \mathrm{~m}$. Taiaçu-SP, outubro de 2004.

\begin{tabular}{ccccc}
\hline Porta-enxerto & $\mathbf{n}^{\circ}$ frutos raleados/planta & $\mathbf{n}^{\circ}$ frutos restantes/planta & $\mathbf{n}^{\circ}$ frutos totais/planta & nota para brotação \\
\hline Clone 05 & $6,00 \mathrm{a}$ & $29,80 \mathrm{a}$ & $35,80 \mathrm{a}$ & $4,33 \mathrm{a}$ \\
Clone 10 & $7,40 \mathrm{a}$ & $31,73 \mathrm{a}$ & $39,13 \mathrm{a}$ & $4,13 \mathrm{a}$ \\
Clone 15 & $7,27 \mathrm{a}$ & $33,73 \mathrm{a}$ & $41,00 \mathrm{a}$ & $4,53 \mathrm{a}$ \\
Okinawa & $8,45 \mathrm{a}$ & $36,45 \mathrm{a}$ & $44,90 \mathrm{a}$ & $4,70 \mathrm{a}$ \\
\hline $\mathrm{F}_{\text {tratam. (ajust.) }}$ & $0,34 \mathrm{NS}$ & $0,66^{\mathrm{NS}}$ & $0,65^{\mathrm{NS}}$ & $2,68^{\mathrm{NS}}$ \\
\hline $\mathrm{F}_{\text {blocos }}$ & $4,22^{*}$ & $4,66^{*}$ & $5,51^{*}$ & $8,93 * *$ \\
\hline $\mathrm{CV}(\%)$ & 49,32 & 22,07 & 24,37 & 7,11 \\
\hline
\end{tabular}

Médias seguidas por letras distintas, na mesma coluna, diferem entre si, pelo teste de Tukey. ** significativo ao nível de $1 \%$ de probabilidade; $*$ significativo ao nível de $5 \%$ de probabilidade; ${ }^{\text {NS }}$ não-significativo.

pois o número de dias entre a aplicação da cianamida hidrogenada e o início da colheita pode ser reduzido, quando a cv. Aurora-1 é enxertada no Clone 05 de umezeiro. De acordo com Young \& Olcott-Reid (1979), o porta-enxerto de pessegueiro 'Siberian C', que reduz o vigor da copa em cerca de $20 \%$, retardou a floração em cinco dias nas três cultivares-copa estudadas, em relação aos porta-enxertos 'Harrow Blood', 'Lovell' e 'Halford'. Este efeito foi observado após o período de repouso vegetativo das plantas, pois o porta-enxerto não influenciou no número de horas de frio necessário para a quebra de dormência.

O número de frutos raleados (Tabela 4) da cv. Aurora-1 foi baixo em todos os porta-enxertos estudados, variando de 6,0 a 8,45, não tendo sido detectada diferença estatística entre os tratamentos, de acordo com o critério adotado para a realização do raleio (Pereira et al., 2002). Os porta-enxertos também não influenciaram no número de frutos restantes por planta, no número total de frutos por planta e nem mesmo na brotação do 'Aurora-1' (Tabela 4). Estes resultados são de grande importância, pois comprovam a viabilidade técnica do uso dos Clones $05 ; 10$ e 15 de umezeiro como porta-enxerto para pessegueiro, com brotações da copa e produções semelhantes às plantas enxertadas no tradicional porta-enxerto 'Okinawa'.

Estes resultados, aliados a todo o conhecimento sobre propagação destes clones por estacas herbáceas, condução dos portaenxertos em sacos plásticos com substrato comercial, viabilidade da enxertia (Nachtigal et al., 1999; Mayer, 2001; Pereira \& Mayer, 2005), resistência a Meloidogyne javanica (Mayer et al., 2003) e M. incognita (Mayer et al., 2005), indicam boas perspectivas de sucesso dos Clones 05; 10 e 15 de umezeiro tornarem-se porta-enxertos adequados para a cultura do pessegueiro e constituírem-se numa moderna tecnologia.

\section{CONCLUSÕES}

Com os resultados obtidos nas condições experimentais adotadas, pode-se concluir que:

1) Os porta-enxertos Clones 05; 10 e 15 de umezeiro e 'Okinawa' não influenciaram de maneira diferenciada no vigor de pessegueiros 'Aurora-1'.

2) O Clone 05 de umezeiro antecipou o pleno florescimento do 'Aurora-1', em relação às plantas enxertadas em 'Okinawa'.

3) Os porta-enxertos estudados não influenciaram no número de frutos por planta e na brotação do 'Aurora-1'.

4) Não foram observados sintomas de incompatibilidade entre os Clones 05; 10 e 15 de umezeiro e do 'Okinawa' propagados por estacas herbáceas com a cv. Aurora-1 de pessegueiro.

\section{AGRADECIMENTOS}

À Fundação de Amparo à Pesquisa do Estado de São Paulo (FAPESP), pela concessão de bolsa de estudos e apoio financeiro para realização deste trabalho.

\section{REFERÊNCIAS}

CAMPO DALL'ORTO, F.A.; OJIMA, M.; BARBOSA, W.; MARTINS, F.P. O nanismo do pessegueiro induzido pela enxertia no damasqueiro-japonês. Pesquisa Agropecuária Brasileira, Brasília, v.27, n.3, p.517-521, 1992.

CAMPO DALL'ORTO, F.A.; BARBOSA, W.; OJIMA, M.; MARTINS, F.P.; FOBÉ, L.A. Comportamento de pessegueiros IAC enxertados no damasqueiro japonês e no pessegueiro 'Okinawa'. In: CONGRESSO BRASILEIRO DE FRUTICULTURA, 13., 1994, Salvador. Anais... Salvador: SBF, 1994. v.3, p.879-880.

GUERRIERO, R.; LORETI, F.; MASSAI, R.; MORINI, S. Comparative trials of several clonal plums, peach seedlings and hybrids tested as peach rootstocks. Acta Horticulturae, The Hague, v.173, p.211221, 1985.

HARTMANN, H.T.; KESTER, D.E. Propagación de plantas. $7^{\text {th }}$ ed. México: Continental, 1978. 810p.

KLENYÁN, T.; HROTKÓ, K.; TIMON, B. Effect of rootstocks on growth of nectarine varieties. Acta Horticulturae, The Hague, v.465, p.225-228, 1998.

LAYNE, R.E.C. Peach rootstocks. In: ROM, R.C.; CARLSON, R.F. Rootstocks for fruit crops. New York: John Wiley \& Sons, 1987. p.185-216.

MAYER, N.A. Propagação assexuada do porta-enxerto umezeiro (Prunus mume Sieb \& Zucc.) por estacas herbáceas. 2001. $109 f$. Dissertação (Mestrado em Produção Vegetal) - Faculdade de Ciências Agrárias e Veterinárias, Universidade Estadual Paulista, 2001.

MAYER, N.A.; PEREIRA, F.M.; SANTOS, J.M. Reação de clones de umezeiro (Prunus mume Sieb. et Zucc.) e cultivares de pessegueiro a Meloidogyne javanica (Treub, 1885) Chitwood, 1949. Revista Brasileira de Fruticultura, Jaboticabal, v.25, n.1, p.181-183, 2003.

MAYER, N.A.; PEREIRA, F.M.; SANTOS, J.M. Resistência de clones de umezeiro e cultivares de pessegueiro a Meloidogyne incognita (Nemata: Heteroderidae). Revista Brasileira de Fruticultura, Jaboticabal, v.27, n.2, p.335-337, 2005.

MAYER, N.A.; PEREIRA, F.M. Vigor de clones de umezeiro e pessegueiro 'Okinawa' propagados' por estacas herbáceas. Pesquisa Agropecuária Brasileira, Brasília, v. 41, n. 5, p. 883887, 2006.

NACHTIGAL, J.C.; PEREIRA, F.M.; CAMPO DALL'ORTO, F.A.; OJIMA, M.; MARTINS, F.P. Propagação vegetativa do umezeiro (Prunus mume) por meio de estacas herbáceas. Revista Brasileira de Fruticultura, Jaboticabal, v.21, n.2, p.226-228, 1999.

NAKAMURA, C.H.; SCARPAREFILHO, J.A.; KLUGE, R.A. Avaliação preliminar do umezeiro como porta-enxerto para pessegueiro e nectarineira. Revista Brasileira de Fruticultura, Jaboticabal, v.21, n.2, p.116-118, 1999.

NIENOW, A.A. Comportamento morfológico, fenológico e produtivo de cultivares de pessegueiro (Prunus persica (L.) Batsch), 
submetidos à poda de renovação após a colheita, na região de Jaboticabal, SP. 1997. 171f. Tese (Doutorado em Agronomia) Faculdade de Ciências Agrárias e Veterinárias, Universidade Estadual Paulista, 1997.

OLIVEIRA, J.B. de; CAMARGO, M.N.; ROSSI, M.; CALDERANOFILHO, B. Mapa pedológico do Estado de São Paulo: legenda expandida. Campinas: Instituto Agronômico; Rio de Janeiro: Embrapa-Solos, 1999. 64p.

PEREIRA, F.M.; NACHTIGAL, J.C.; ROBERTO, S.R. Tecnologia para a cultura do pessegueiro em regiões tropicais e subtropicais. Jaboticabal: FUNEP, 2002. 62p.
PEREIRA, F.M.; MAYER, N.A. Pessegueiro: tecnologias para a produção de mudas. Jaboticabal: Funep, 2005. 65p.

RASEIRA, M. do C.B.; NAKASU, B.H. Pessegueiro. In: BRUCKNER, C.H. Melhoramento de fruteiras de clima temperado. Viçosa: UFV, 2002.p.89-126.

YOUNG, E.; OLCOTT-REID, B. Siberian C rootstock delays bloom of peach. Journal American Society for Horticultural Science, Alexandria, v.104, n.2, p.178-181, 1979. 